\title{
Detailed registration of care in midwifery practices in the Netherlands: an opportunity for research within a healthy pregnant population
}

\author{
A. Pouwels ${ }^{*} \mathbb{D}$, P. Offerhaus, A. Merkx, B. Zeegers and M. J. Nieuwenhuijze
}

\begin{abstract}
Background: Research in maternity care is often conducted in mixed low and high-risk or solely high-risk populations. This limits generalizability to the low-risk population of pregnant women receiving care from Dutch midwives. To address this limitation, 24 midwifery practices in the Netherlands bring together routinely collected data from medical records of pregnant women and their offspring in the VeCaS database. This database offers possibilities for research of physiological pregnancy and childbirth. This study explores if the pregnant women in VeCaS are a representative sample for the national population of women who receive primary midwife-led care in the Netherlands.
\end{abstract}

Methods: In VeCaS we selected a low risk population in midwife-led care who gave birth in 2015. We compared population characteristics and birth outcomes in this study cohort with a similarly defined national cohort, using Chi Square and two side t-test statistics. Additionally, we describe some birth outcomes and lifestyle factors.

Results: Midwifery practices contributing to VeCaS are spread over the Netherlands, although the western region is underrepresented. For population characteristics, the VeCaS cohort is similar to the national cohort in maternal age (mean 30.4 years) and parity (nulliparous women: $47.1 \%$ versus $45.9 \%$ ). Less often, women in the VeCaS cohort have a non-Dutch background (15.7\% vs 24.4\%), a higher SES (9.9\% vs 23.7\%) and live in an urbanised surrounding (4.9\% vs $24.8 \%$ ). Birth outcomes were similar to the national cohort, most women gave birth at term (94.9\% vs $94.5 \%$ between $37+{ }^{0}-41+{ }^{6}$ weeks), started labour spontaneously (74.5\% vs $75.5 \%$ ) and had a spontaneous vaginal birth (77.4\% vs $77.6 \%), 16.9 \%$ had a home birth. Furthermore, $61.1 \%$ had a normal pre-pregnancy BMI, and $81.0 \%$ did not smoke in pregnancy.

Conclusions: The VeCaS database contains data of a population that is mostly comparable to the national population in primary midwife-led care in the Netherlands. Therefore, the VeCaS database is suitable for research in a healthy pregnant population and is valuable to improve knowledge of the physiological course of pregnancy and birth. Representativeness of maternal characteristics may be improved by including midwifery practices from the urbanised western region in the Netherlands.

Keywords: Pregnancy, Data collection, VeCaS

\footnotetext{
* Correspondence: anneke.pouwels@av-m.nl

Research Centre for Midwifery Science, Zuyd University, Maastricht, the Netherlands

C C The Author(s). 2020 Open Access This article is licensed under a Creative Commons Attribution 4.0 International License, which permits use, sharing, adaptation, distribution and reproduction in any medium or format, as long as you give appropriate credit to the original author(s) and the source, provide a link to the Creative Commons licence, and indicate if changes were made. The images or other third party material in this article are included in the article's Creative Commons licence, unless indicated otherwise in a credit line to the material. If material is not included in the article's Creative Commons licence and your intended use is not permitted by statutory regulation or exceeds the permitted use, you will need to obtain permission directly from the copyright holder. To view a copy of this licence, visit http://creativecommons.org/licenses/by/4.0/ The Creative Commons Public Domain Dedication waiver (http://creativecommons.org/publicdomain/zero/1.0/) applies to the data made available in this article, unless otherwise stated in a credit line to the data.
} 


\section{Background}

Most primary care midwives in the Netherlands are organized in independent midwifery practices in the community, and care for healthy women with uncomplicated pregnancies and births. Primary midwife-led care emphasizes the normality of the reproductive process, recognizing that pregnancy and childbirth are physiological processes. Midwives are 'gatekeepers' and refer women to a secondary care obstetric team if risk factors or complications arise during pregnancy, labour or after birth. Interventions such as augmentation of labour, pharmacological pain relief, continuous foetal monitoring or instrumental birth are only accessible in secondary care [1-3]. Women who start their antenatal care in primary, midwife-led care are free to choose a birth at home, in a birth centre or in the hospital, attended by their own primary care midwife. When women are referred to obstetrician-led care during the antenatal or intrapartum period because of an increased risk or complication, these women give birth in the hospital, attended by a secondary care obstetric team (hospital-based midwives, residents and obstetricians) [4].

Currently, evidence-based midwifery in Dutch maternity care is often based on national and international research performed in mixed low and high-risk or solely high-risk populations. This limits generalizability of evidence to a low-risk population of healthy, pregnant women in primary midwife-led care.

The Midwifery Science department from Zuyd University in Maastricht has set up the Midwifery Case Registration System (Verloskundig Casusregistratie Systeem, VeCaS) to address the need for research in a healthy, low-risk population. $\mathrm{VeCaS}$ is a database, which includes anonymized quantitative data extracted from the medical files of women receiving care in 24 Dutch midwifery practices from 2012 onwards. VeCaS contains information about each professional contact with a woman and her baby during the prenatal, natal and postnatal period. It collects data such as blood pressure, maternal weight and length, ultrasounds, abdominal palpations, birth mode, birthweight, other neonatal measures, and information about referrals and consultations with other professionals. $\mathrm{VeCaS}$ collects information on pregnancies and births in much more detail than available in the existing database Perined from the Netherlands Perinatal Registry. This national registry routinely collects and combines a limited number of items on antenatal, intrapartum and postnatal care in four separate national registries; one for primary midwife-led care (LVR1), one for maternity care by general practitioners (LVR1h), one for obstetrician-led care (LVR2), and one for neonatal care (LNR). Perined contains data on approximately $98 \%$ of all births in the Netherlands [5].

The midwives participating in $\mathrm{VeCaS}$ are instructed verbally about collection and registration of the data to improve data validity. Subsequently, together with the participating midwives, a consensus manual with definitions of the variables has been created. Midwifery practices bi-yearly receive a summary of their own registered data for feedback on their quality of registration to optimize data collection and/or registration. The VeCaS database increases with approximately 6.000 records each year. Informed consent is obtained from each woman before extracting the anonymized data from the medical file to $\mathrm{VeCaS}$. On average 10 (range 0-50) women per practice per year do not provide informed consent and are not included. Ethical approval for the database was obtained from the regional Medical Research Ethics Committee Maastricht (nr 09-4-061).

Research in the $\mathrm{VeCaS}$ database addresses the needs for more evidence on the physiological course of pregnancy and birth. The Netherlands can provide a healthy population database since primary midwife-led care in the Netherlands is well known internationally for its low-intervention rate and its high homebirth rate. This might be of interest of other countries as well.

The aim of this study is to examine if pregnant women registered in $\mathrm{VeCaS}$ offer a representative reflection of the national population of women who receive primary care in midwifery practices in the Netherlands, considering maternal and pregnancy characteristics.

\section{Methods \\ Study population}

We created a study cohort that included all women registered in $\mathrm{VeCaS}$ who gave birth in 2015, and who received antenatal care up to at least 28 weeks of gestation in one of the 24 participating midwifery practices. Likewise, we created a national cohort using the Perined database. The study populations in both cohorts, being in primary midwife-led care at 28 weeks of pregnancy, are, by definition, considered to be low risk.

We choose 2015, because complete data on pregnancy and birth were available in $\mathrm{VeCaS}$ as well as Perined at the start of the study. We excluded women who gave birth before 28 weeks or at an unknown gestational age, women who were transferred to obstetrician-led care before 28 weeks, women who had a multiple pregnancy and women whose antenatal care in the midwifery practice ended for non-medical reasons such as moving out of the practice area (see Fig. 1 for a flowchart of the VeCaS cohort).

\section{Analysis}

We compared the VeCaS cohort with the created national cohort on age, parity, background (Dutch or nonDutch), social economic status (SES) and level of urbanization. The two latter characteristics were based on the four digits of the postal code [6]. We used Chi 


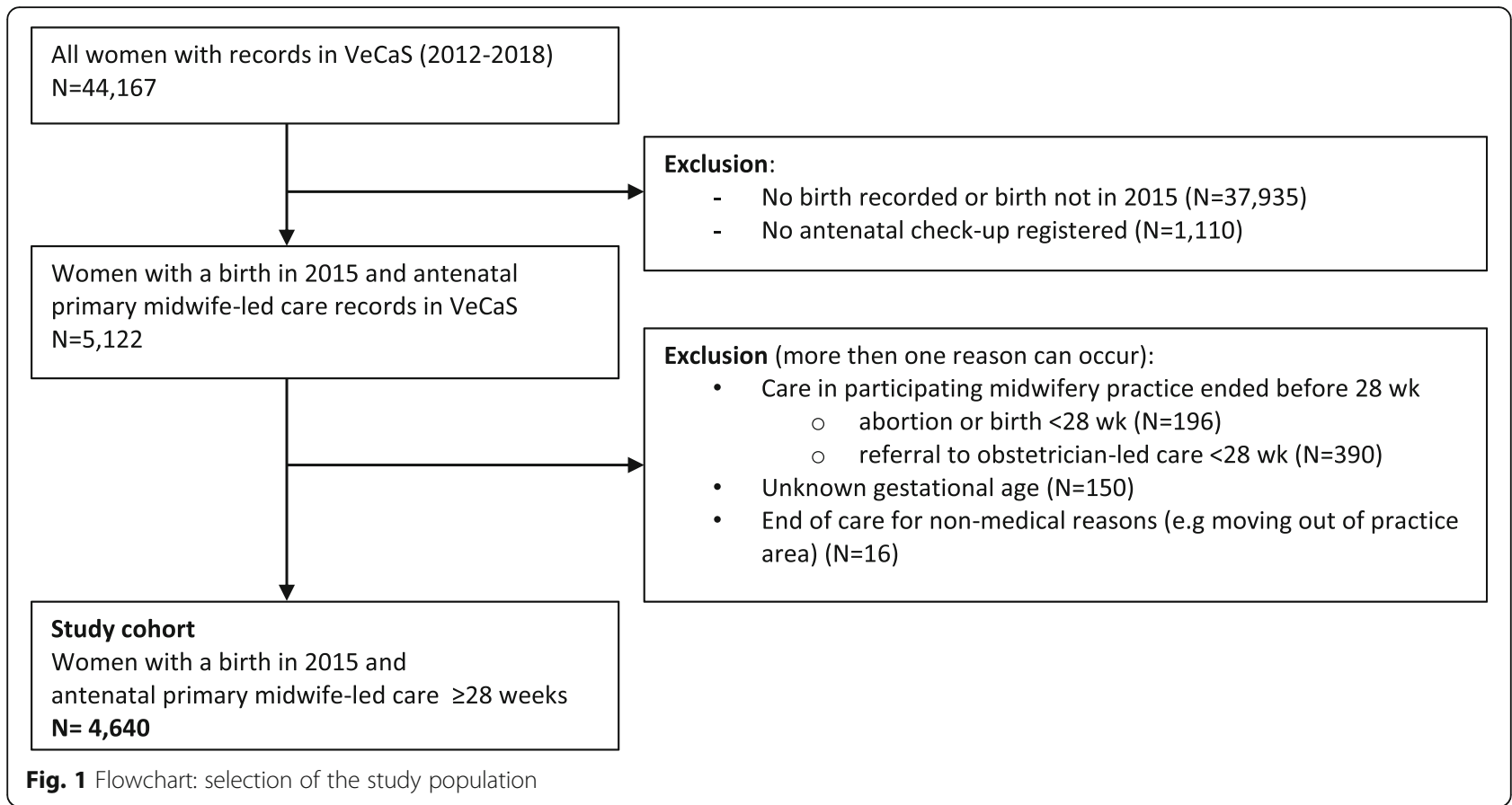

Square or two side t-test statistics to test whether these differences are statistically significant. Analyses were performed with SPSS 25.

Additionally, we describe other birth and pregnancy characteristics (gestational age at birth, start of labour, mode of birth, place and level of care at birth, and birthweight) of the $\mathrm{VeCaS}$ cohort compared with the national cohort.

We also describe the body mass index (BMI) and smoking behaviour in the $\mathrm{VeCaS}$ cohort. We cannot compare these life style characteristics with the created national cohort, since these are not reliably available in the Perined database.

\section{Results}

\section{Practice characteristics}

The 24 midwifery practices participating in $\mathrm{VeCaS}$ (2015) were situated throughout the Netherlands (see Fig. 2). The distribution shows more practices to the southeast compared to the western part of the Netherlands. Most of the practices $(N=13)$ were located within a rural region, the remaining were located within an urban region $(N=5)$ or a combination of both $(N=$ $6)$. The number of women cared for in the practices varied from 93 to 532, with an average of 294. Most of the practices were organized as a duo with two midwives $(N=4)$ or as a group with three midwives or more $(N=20)$. No solo practice was represented. The midwives had a mean age of 41 years (median age 38; range 22-61).

\section{Population characteristics}

The VeCaS cohort contained records of 4640 women. Using the same inclusion criteria, the national cohort contained records of 127,818 women in 2015. Maternal age and parity showed no relevant differences between both cohorts. The mean maternal age in the $\mathrm{VeCaS}$ cohort and the national cohort was 30.4 years (SD 4.5, SD 4.6); $47.1 \%$ women in the $\mathrm{VeCaS}$ cohort were nulliparous and $52.9 \%$ multiparous, compared to $45.9 \%$ nulliparous and $54.1 \%$ multiparous women in the national cohort.

Other characteristics were distributed less equally. In $\mathrm{VeCaS}, 84.1 \%$ of the women had a Dutch background compared to $75.6 \%$ of the women in Perined. In the $\mathrm{VeCaS}$ cohort women with a higher SES (9.9\%) were underrepresented compared to the national cohort (23.7\%). Furthermore, in the $\mathrm{VeCaS}$ cohort most women lived in middle $(32.4 \%)$ or low (23.4\%) urbanized regions whereas in the Perined cohort more women lived in very high $(24.8 \%)$ and high (25.6\%) urbanized regions.

Lifestyle characteristics in VeCaS showed that $61.1 \%$ of the women had a normal pre-pregnancy BMI, and $81.0 \%$ did not smoke in pregnancy (see Table 1).

\section{Birth and pregnancy characteristics}

Within the VeCaS cohort, most women gave birth at term ( $94.9 \%$ from $37^{+0}$ to $41^{+6}$ weeks). Labour mostly started spontaneously (74.5\%) and most women experienced a spontaneous vaginal birth (77.4\%). This is comparable with the national cohort (see Table 2). Both in the $\mathrm{VeCaS}$ and in the national cohort, $16.9 \%$ of the women experienced a home birth. An equal proportion 


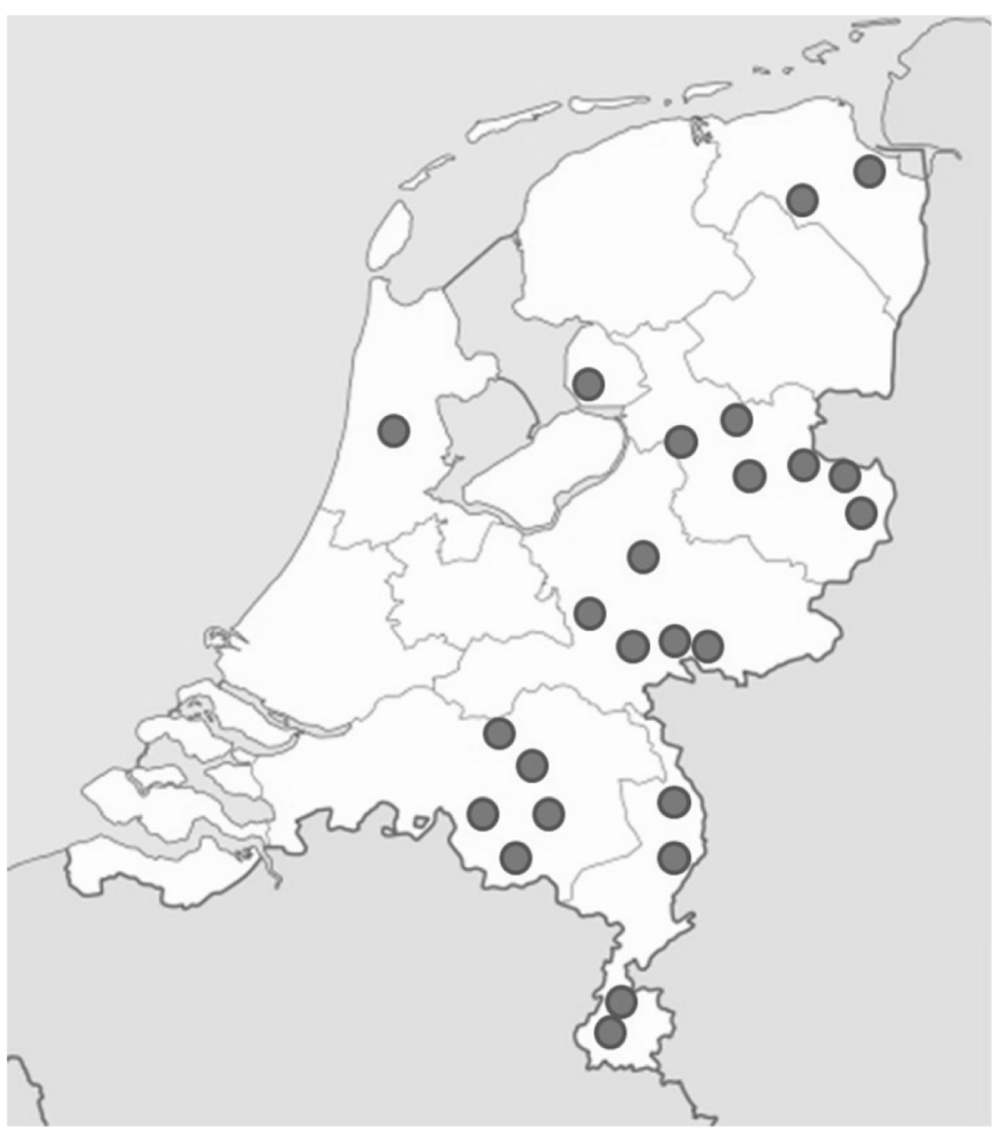

Fig. 2 Location of 24 midwifery practices participation in VeCaS in 2015 in the Netherlands

of women was referred during pregnancy or labour to an obstetric team and gave birth in the hospital in secondary care: $64.7 \%$ in the $\mathrm{VeCaS}$ cohort and $63.9 \%$ in the national cohort. The average birthweight was $3465 \mathrm{~g}$ (SD 522 ) in the $\mathrm{VeCaS}$ cohort compared to $3469 \mathrm{~g}$ (SD 513) in the national cohort.

\section{Discussion}

In this study, we explored whether the pregnant women registered in $\mathrm{VeCaS}$ are a representative reflection of the national population of women who receive primary midwife-led care in midwifery practices in the Netherlands. Based on age and parity, the $\mathrm{VeCaS}$ cohort corresponds adequately with the cohort derived from the national perinatal database Perined. Both cohorts are also comparable regarding birth characteristics such as home births, spontaneous start of labour and spontaneous vaginal births. These birth characteristics reflect the healthy, low-risk profile of the $\mathrm{VeCaS}$ cohort.

We were not able to compare lifestyle characteristics within the $\mathrm{VeCaS}$ cohort, as reliable information on smoking behaviour and BMI are not available in Perined. However, national statistics suggest that non-smoking behaviour in our cohort $(81.0 \%$ non-smokers $)$ was somewhat more frequent than in the general population of women aged 25-45 years in 2015 (75.6\% nonsmokers), and that some more women had a normal BMI compared to women in this age category in 2015 (61.1 vs $57.9 \%)$ [7].

Women with a non-Dutch ethnic background, SES classified as higher and women who lived in a very high or high urbanized region are underrepresented within the $\mathrm{VeCaS}$ cohort. It is likely that the representativeness of $\mathrm{VeCaS}$ for the population in primary midwife-led care in the Netherlands will improve by including midwifery practices from the highly urbanized region called the Randstad' in the western region in the Netherlands. In collaboration with the Amsterdam/Groningen Academy of Midwifery (AVAG) new practices in this region are being recruited and the first records are included in the VeCaS database since 2018.

Characteristics of the participating midwifery practices show a relative young age of midwives (median age 38 ). This corresponds with the midwifery profession in the Netherlands, where $64 \%$ of midwives is under 40 years of age [8]. Midwifery practices organized as solo are not represented in the $\mathrm{VeCaS}$ database at this moment. Since only $5 \%$ of the primary care midwives in the 
Table 1 Characteristics women in the VeCaS cohort compared to national cohort (2015)

\begin{tabular}{|c|c|c|c|c|c|}
\hline & VeCaS cor & & National coh & & \\
\hline & $N=4640$ & $100 \%$ & $N=127,818$ & $100 \%$ & \\
\hline Maternal age & & & & & \\
\hline All women (mean, SD) & 30.4 & (SD 4.5) & 30.4 & (SD 4.6) & $p=1.00$ \\
\hline Primiparous women (mean, SD) & 28.8 & (SD 4.3) & 28.9 & (SD 4.6) & $p=0.3174$ \\
\hline
\end{tabular}

Age in categories

$$
\begin{gathered}
\text { All women } \\
<20 \mathrm{yr} \\
20-24 \mathrm{yr} \\
25-29 \mathrm{yr} \\
30-34 \mathrm{yr} \\
35-39 \mathrm{yr} \\
\geq 40 \mathrm{yr}
\end{gathered}
$$

\section{Parity}

PO

P1

$\mathrm{P} 2+$

missing

\section{Background}

Dutch
Non-Dutch
missing

missing

\section{Social Economic Status (SES) ${ }^{\mathrm{a}}$}

Higher
Middle
Lower
missing

\section{Urbanization $^{\text {b }}$}

Very high $(>2500)$
High (1500-2500)
Middle (1000-1500)
Low (500-1000)
very low (100-500)
missing

\section{BMI in $\mathrm{kg} / \mathrm{m}^{2}$}

Low $(<18,5)$
Normal $(18,5-24,9)$
Overweight $(25-29,9)$
Obesitas $(\geq 30)$
missing

\section{Smoking in pregnancy}

$\begin{array}{lll}\text { No } & 3676 & 81.0 \% \\ \text { Stopped in 1st trimester } & 367 & 8.1 \% \\ \text { Yes } & 497 & 10.9 \% \\ \text { missing } & 100 & \end{array}$

abased on 4 digits of the postal code

b based on 4 digits of the postal code, number of households $/ \mathrm{km}^{2}$

$47.1 \%$

$84.1 \%$

227

$15.7 \%$

$9.9 \%$

2538

$55.2 \%$

$\begin{array}{ll}149 & 3.2 \% \\ 2777 & 61.1 \% \\ 1088 & 23.9 \% \\ 530 & 11.7 \% \\ 96 & \end{array}$

96

$81.0 \%$

$8.1 \%$

$0.9 \%$

$\begin{array}{lll}0.6 \% & 1125 & 0.9 \% \\ 8.0 \% & 12,072 & 9.4 \% \\ 33.9 \% & 41,138 & 32.2 \% \\ 38.8 \% & 49,438 & 38.7 \% \\ 16.1 \% & 20,885 & 16.3 \% \\ 2.5 \% & 3160 & 2.5 \%\end{array}$

58,608

$45.9 \%$

$x^{2}=16.757, d f=2, p=0.0002$

46,010

$36.0 \%$

23,198

$18.1 \%$

2

96,589

$75.6 \%$

$X^{2}=171.058, d f=1, p<0.0001$

31,229

$24.4 \%$

30,149

$23.7 \%$

$X^{2}=499.183, d f=2, p<0.0001$

55,949

$44.0 \%$

41,146

$32.3 \%$

574

$\begin{array}{ll}31,693 & 24.8 \% \\ 32,707 & 25.6 \% \\ 23,989 & 18.8 \% \\ 21,991 & 17.2 \% \\ 17,232 & 13.5 \%\end{array}$

206 $x^{2}=1463.241, d f=4, p<0.0001$ 
Table 2 Description of birth characteristics in the VeCaS cohort compared to national cohort (2015)

\begin{tabular}{|c|c|c|c|c|}
\hline & \multicolumn{2}{|c|}{ VeCaS cohort } & \multirow{2}{*}{$\begin{array}{l}\text { National cohor } \\
N=127,818\end{array}$} & \multirow[b]{2}{*}{$100 \%$} \\
\hline & $N=4640$ & $100 \%$ & & \\
\hline \multicolumn{5}{|l|}{ Gestational age in weeks } \\
\hline$<37$ weeks & 196 & $4.2 \%$ & 5121 & $4.1 \%$ \\
\hline $37^{0}-41^{6}$ weeks & 4403 & $94.9 \%$ & 119,429 & $94.5 \%$ \\
\hline$\geq 42$ weeks & 41 & $0.9 \%$ & 1836 & $1.5 \%$ \\
\hline \multicolumn{5}{|l|}{ Start of labour } \\
\hline Spontaneous & 3403 & $74.5 \%$ & 96,547 & $75.5 \%$ \\
\hline Induction & 893 & $19.6 \%$ & 23,853 & $18.7 \%$ \\
\hline Elective caesarean section & 271 & $5.9 \%$ & 7416 & $5.8 \%$ \\
\hline missings & 73 & & & \\
\hline \multicolumn{5}{|l|}{ Mode of birth } \\
\hline Spontaneaous vaginal & 3506 & $77.4 \%$ & 98,846 & $77.6 \%$ \\
\hline Instrumental vaginal & 390 & $8.6 \%$ & 10,504 & $8.2 \%$ \\
\hline Caesarean section & 634 & $14.0 \%$ & 18,000 & $14.1 \%$ \\
\hline missings & 110 & & & \\
\hline \multicolumn{5}{|l|}{ Place and level of care at birth } \\
\hline Home (midwife, primary care) & 776 & $16.9 \%$ & 21,632 & $16.9 \%$ \\
\hline Birth centre (midwife, primary care) & 101 & $2.2 \%$ & 3943 & $3.1 \%$ \\
\hline Hospital (midwife, primary care) & 748 & $16.2 \%$ & 20,528 & $16.2 \%$ \\
\hline Hospital (obstetric team, secondary care) & 2977 & $64.7 \%$ & 81,674 & $63.9 \%$ \\
\hline missings & 38 & & 41 & \\
\hline \multicolumn{5}{|l|}{ Birthweight } \\
\hline Mean & 3465 & SD (522) & 3469 & SD (513) \\
\hline \multicolumn{5}{|l|}{ Birthweight categories } \\
\hline$<2500 \mathrm{~g}$ & 154 & $3.3 \%$ & 4267 & $3.3 \%$ \\
\hline $2500-4500 \mathrm{~g}$ & 4368 & $94.9 \%$ & 120,844 & $94.7 \%$ \\
\hline$>4500 \mathrm{~g}$ & 82 & $1.8 \%$ & 2459 & $1.9 \%$ \\
\hline missings & 36 & & 248 & \\
\hline
\end{tabular}

Netherlands works in a solo practice, [8], we assume that the underrepresentation of solo midwifery practices do not affect the representativeness of the $\mathrm{VeCaS}$ population.

The $\mathrm{VeCaS}$ database is highly suitable for research within a healthy pregnant population. The information collected throughout pregnancy and childbirth within the $\mathrm{VeCaS}$ database creates a possibility to describe in detail characteristics of healthy pregnancies and the care that was offered. In our study cohort a population was selected who received antenatal care from their midwife up to at least 28 weeks of gestation, reflecting the population who receive primary midwife-led care in the Netherlands. The database offers the possibility to select records of women who stay in primary midwife-led care until the start of term labour - without antenatal referral to obstetrician-led care -, this group reflects a population that experienced a pregnancy without significant complications. For example, if we would select records this group of women in our study cohort ( $n=2702 ; 58.2 \%$ ), $86.4 \%$ of these women experienced a spontaneous vaginal birth and $28.1 \%$ a home birth (data not shown). Depending on the research question, an even healthier sub-population within the $\mathrm{VeCaS}$ database can also be defined, for instance only women with healthy life style characteristics. Selecting only women with a normal prepregnancy BMI and non-smoking behaviour provides an opportunity to investigate for example physiological changes in blood pressure, weight gain or to develop curves for birthweight appropriate for gestational age.

\section{Conclusion}

The VeCaS database contains rich pregnancy and birth information on a population that is mostly comparable to the national population in primary midwife-led care in the Netherlands, considering maternal age, parity, gestational age, birthweight, and birth outcomes. The 
database represents a healthy population and therefore offers an ideal opportunity to improve knowledge on the physiological course of pregnancy and birth. By including more midwifery practices located in the highly urbanized western region of the Netherlands, representativeness of maternal characteristics such as SES, urbanization and ethnicity can be further improved in the $\mathrm{VeCaS}$ database.

\section{Abbreviations}

AVAG: Amsterdam/Groningen Academy of Midwifery; BMI: Body Mass Index; SES: Social Economic Status; SPSS: Statistical Package for the Social Sciences; VeCaS: Verloskundig Casusregistratie Systeem (Midwifery Case Registration System)

\section{Acknowledgements}

We acknowledge all VeCaS midwives for their efforts and for their consent for research.

\section{Authors' contributions}

All authors (AP, PO, BZ, AM and MN) contributed to the conception and design of the study. AP and PO performed the statistical analysis, all authors were involved in the interpretation of the data and results. AP drafted the manuscript. All authors read and approved the final manuscript.

\section{Funding}

This study is performed without funding

\section{Availability of data and materials}

The datasets used and/or analyzed during the current study are available from the corresponding author on reasonable request.

\section{Ethics approval and consent to participate}

Ethical approval for the VeCaS database was obtained from the regional Medical Research Ethics Committee Maastricht (nr 09-4-061). Because of its non-invasive nature, this type of research does not require further ethical approval in the Netherlands. Verbal informed consent was obtained from each woman before extracting the data from the medical file to VeCaS. The extracted data are anonymized and cannot be related to individual women.

\section{Consent for publication}

Not Applicable.

\section{Competing interests}

One of the authors, dr. M. Nieuwenhuijze, is a member of the editorial board of BMC Pregnancy and Childbirth.

Received: 14 February 2020 Accepted: 9 June 2020

Published online: 16 June 2020

\section{References}

1. Van Haaren-ten Haken TM, Hendrix MJC, Nieuwenhuiize MJ, Budé L, de Vries RG, Nijhuis JG. Preferred place of birth: characteristics and motives of low-risk nulliparous women in the Netherlands. Midwifery. 2012;28:609-18.

2. Offerhaus PM, Hukkelhoven CWPM, de Jonge A, van der Pal-de Bruin KM, Scheepers PL, Lagro-Janssen AL. Persisting rise in referrals during labor in primary midwife-led care in the Netherlands. Birth. 2013:40(3):192-201.

3. Offerhaus PM, Geerts C, de Jonge A, Hukkelhoven CWPM, Twisk JWR, LagroJanssen ALM. Variation in referrals to secondary obstetrician-led care among primary midwifery care practices in the Netherlands: a nationwide cohort study. BMC Pregnancy and Childbirth. 2015;15:42.

4. Cronie D, Rijnders M, Buitendijk S. Diversity in the scope and practice of hospital-based midwives in the Netherlands. Journal of Midwifery \& Women's Health. 2012:57:469-75.

5. Perined: Perinatal care in the Netherlands 2016. Utrecht; 2019. Available from: https://www.perined.nl/publicaties1/publicaties/jaarboeken. [cited 2019 September 26].

6. van Andel W, Guldenmond T, Faqiri F. SCP Statusscores 2014. Den Haag: SCP; 2016
7. CBS StatLine. [Lifestyle and prevention: gender, age, personal characteristics 2014-2015.] Leefstijl en preventief: geslacht, leeftijd, persoonskenmerken 2014-2015. [updated 2018 May 31; cited 2019 December 5]. Available from: https://opendata.cbs.nl/statline.

8. Nivel. [Figures from the midwifery registration, 2016.] Cijfers uit de registratie van verloskundigen, peiling 2016. Utrecht; 2017. Available from: https://www.nivel.nl/sites/default/files/cijfers-uit-de-registratie-vanverloskundigen-peiling-jan-2016.pdf. [cited 2019 September 26].

\section{Publisher's Note}

Springer Nature remains neutral with regard to jurisdictional claims in published maps and institutional affiliations.
Ready to submit your research? Choose BMC and benefit from:

- fast, convenient online submission

- thorough peer review by experienced researchers in your field

- rapid publication on acceptance

- support for research data, including large and complex data types

- gold Open Access which fosters wider collaboration and increased citations

- maximum visibility for your research: over $100 \mathrm{M}$ website views per year

At $\mathrm{BMC}$, research is always in progress.

Learn more biomedcentral.com/submissions 